archives

of thermodynamics

Vol. 34(2013), No. 4, 35-49

DOI: $10.2478 /$ aoter-2013-0028

\title{
Analysis of the use of adsorption processes in trigeneration systems
}

\section{ANDRZEJ GRZEBIELEC* ARTUR RUSOWICZ}

Warsaw University of Technology, Institute of Heat Engineering, Nowowiejska 21/25, 00-665 Warszawa, Poland

\begin{abstract}
The trigeneration systems for production of cold use sorption refrigeration machines: absorption and adsorption types. Absorption systems are characterized namely by better cooling coefficient of performance, while the adsorptive systems are characterized by the ability to operate at lower temperatures. The driving heat source temperature can be as low as 60-70 ${ }^{\circ} \mathrm{C}$. Such temperature of the driving heat source allows to use them in district heating systems. The article focuses on the presentation of the research results on the adsorption devices designed to work in trigeneration systems.
\end{abstract}

Keywords: Adsorption refrigeration; Trigeneration; Sorption chiller

\section{Nomenclature}

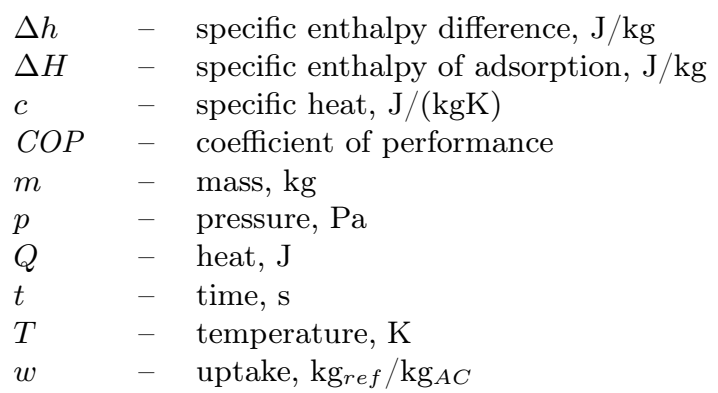

\footnotetext{
${ }^{*}$ Corresponding Author. E-mail: angrzeb@itc.pw.edu.pl
} 


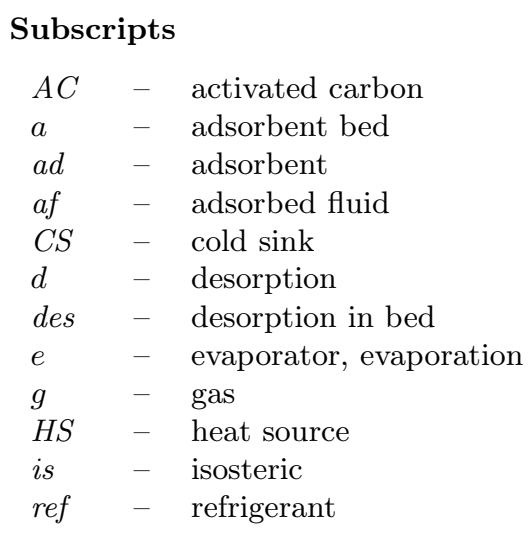

\section{Introduction}

In the European Union, United States and Japan in view of the continued increase in quality of life, air conditioning has become a standard, without which it is difficult to imagine the human existence. Air conditioning systems are usually built as vapor compression types. These systems are powered by electricity. Increasing the standard of living quite significantly contributes to the increase in electricity consumption and thus $\mathrm{CO}_{2}$ emissions. Figure 1 presents the energy consumption of common public buildings in Poland. The demand for cooling power is so high that it seems appropriate to use trigeneration.

Power plants operate in cogeneration systems and produce both electricity and heat. Due to seasonal temperature changes, production is not sustainable and it happens quite often, especially during the summer months, the heat is released to the environment. The idea for use of the heat in summer and at the same time reducing electricity consumption is trigeneration. At the same time it is appropriate to produce cold from heat, and not from the electricity, preferably with the heat which is currently transferred into the environment [7]. For this reason, in the sense of the trigeneration application only thermally driven chillers can be used. They are commonly referred to as TDC. From a technical point of view they are absorption or adsorption refrigeration devices. Currently, in large existing systems there are mainly absorber systems used.

In Europe, there are several systems that produce electricity, heat and cold. These systems are located in Stockholm, Copenhagen, Munich and Vienna. Cold water is produced directly in plants and distributed to end-users 
in the same way as the hot water. In Poland, the pilot plant was established in Poznan, where nearly 0.5 MW of cooling is used to air conditioning plant offices.

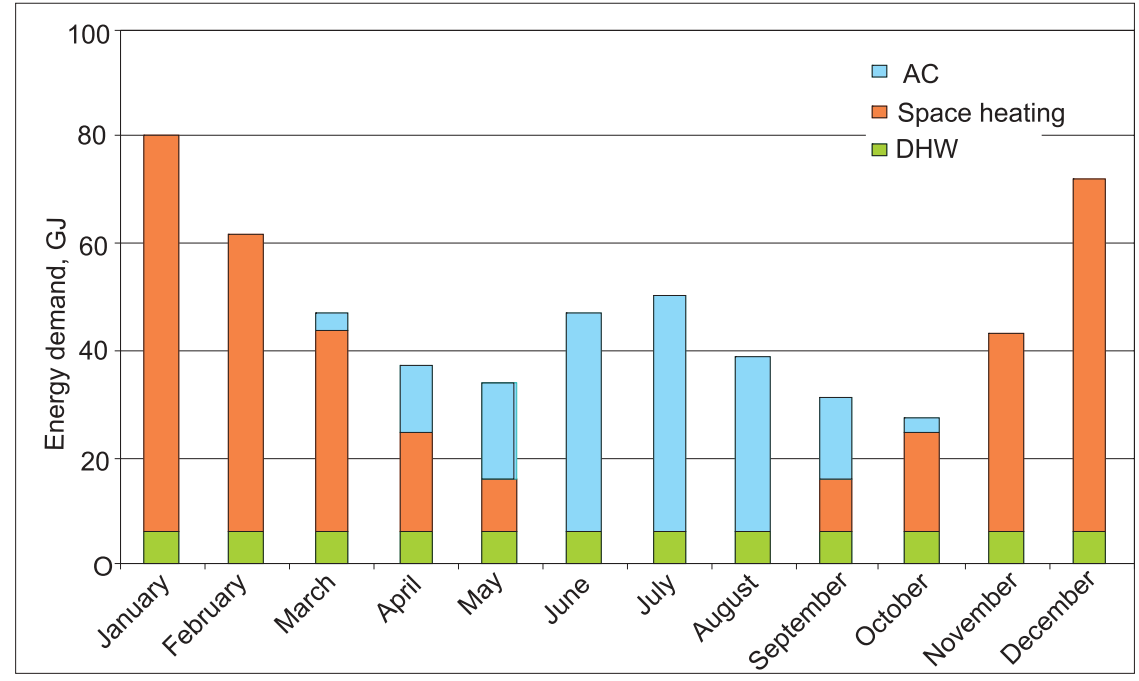

Figure 1. The energy demand of a small office building, located in Warsaw [8]: AC - air conditioning, DHW - domestic hot water.

\section{Trigeneration systems}

Trigeneration systems due to the construction and connection to the electricity and district heating grids are divided into three types:

- decentralized system,

- centralized system with decentralized cold generation,

- centralized system.

\subsection{Decentralized system}

The system is built in such a way that the micro-CHP and TDC units are located directly in the end-user buildings where the heat, cold or electricity generation occurs. This type of system is shown in Fig. 2. The system is 
connected to the electricity grid, and designed to meet the needs for heat and cold demand of the end-user. The electricity is consumed on-site or sold to the grid depending on the demand. The main problem of decentralized systems is their low efficiency, compared with the centralized systems, and low pollution emission control. Another serious problem is that the grids are not suitable for large number of small sources of electricity.

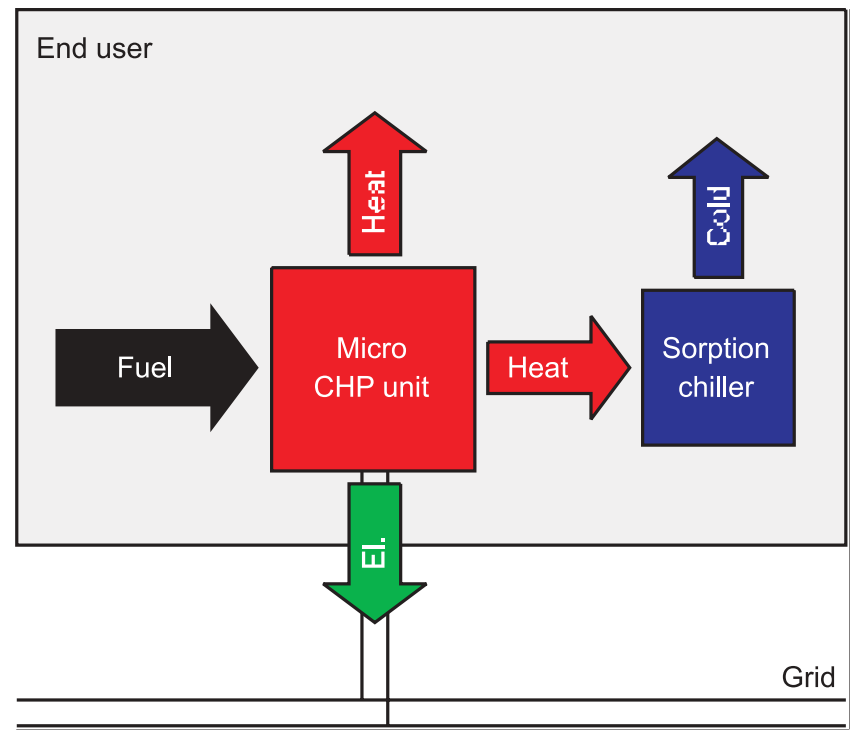

Figure 2. Decentralized trigeneration system.

\subsection{Centralized system with decentralized cold generation}

In the case of centralized system with decentralized cold generation, the system looks in such a way that the power plant produces heat and electricity. Cold production occurs at the end-user's place. The system design is presented in Fig. 3. In such solution, the TDC must be driven by energy from the district heating; and here comes the problem. Temperature of the network water is quite strongly dependent on the time of year. In winter, it's temperature reaches, whereas $120{ }^{\circ} \mathrm{C}$, in summer it drops to about $70{ }^{\circ} \mathrm{C}$ [10]. Cold is required mostly during the summer, so the sorption device must be adapted to work with such a low temperature. This causes the fact that the designs with absorbers are not suitable for this kind of technology. There can only be used the adsorption units. 


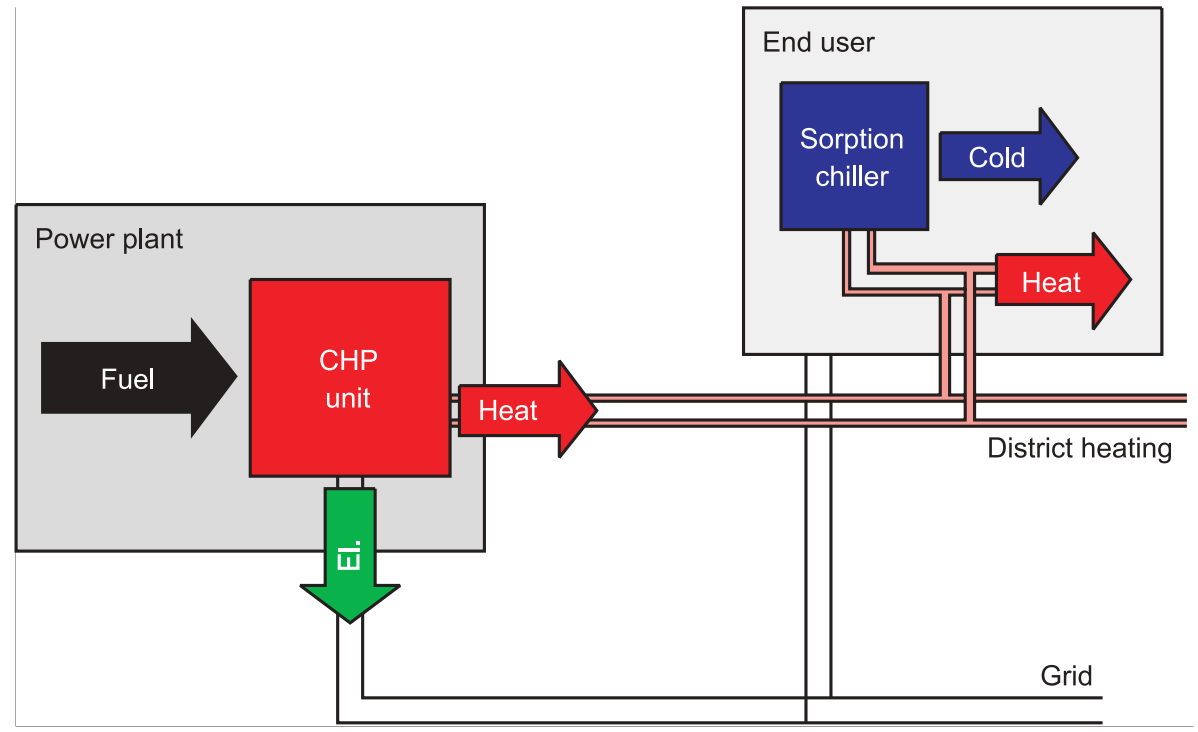

Figure 3. Centralized trigeneration system with decentralized cold generation.

\subsection{Centralized trigeneration system}

In the case of a centralized system (Fig. 4) electricity, heat and cold are generated directly at the plant side. In this solution, the driving heat source may be substantially at any temperature. Nevertheless, it turns out that even here the best solution is when the devices are driving the TDC for the lowest temperature.

\section{Adsorption versus absorption}

As already mentioned, the systems for the production of cold from heat from a technical point of view are absorption or adsorption refrigeration systems. Absorption systems used in air conditioning work with the water as a working fluid and lithium bromide as the absorbent. If lower temperature is needed at the evaporator, there are ammonia absorption systems used where ammonia is the working fluid and water is the absorbing material. The Fig. 5 shows the principle of absorption refrigeration devices. The heat generator is provided which is designed to evaporate the refrigerant. In absorption systems, it is recommended that the driving heat source temperature should be over $110{ }^{\circ} \mathrm{C}[9]$. 


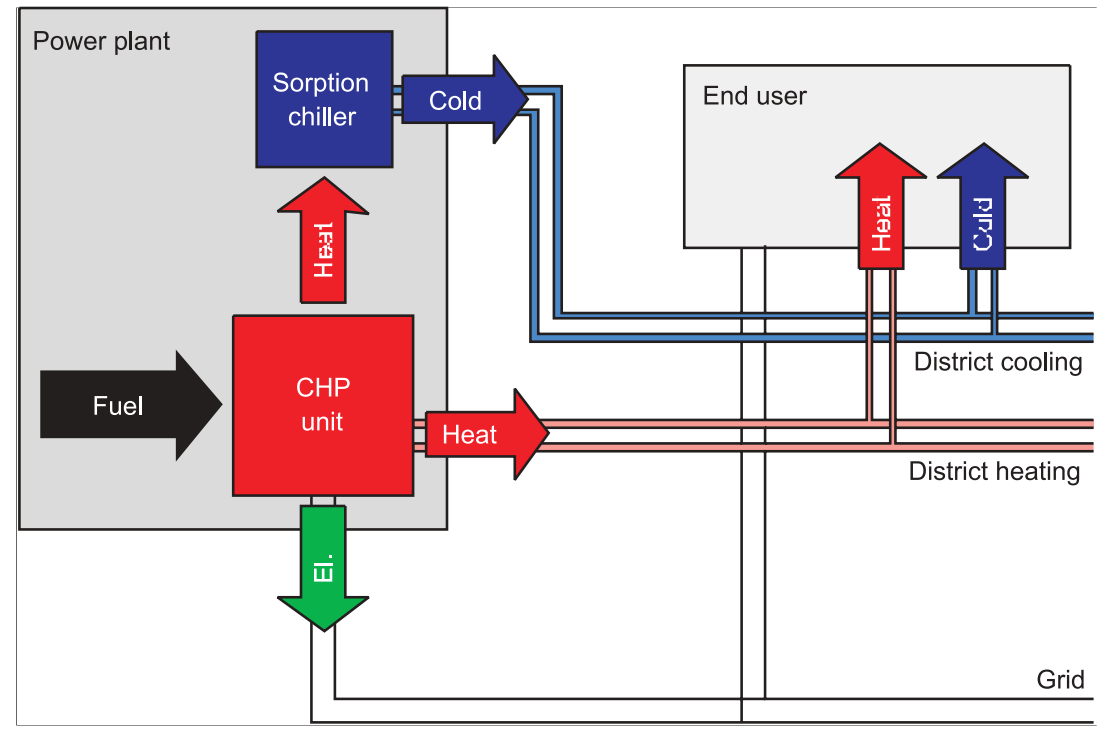

Figure 4. Centralized trigeneration system.

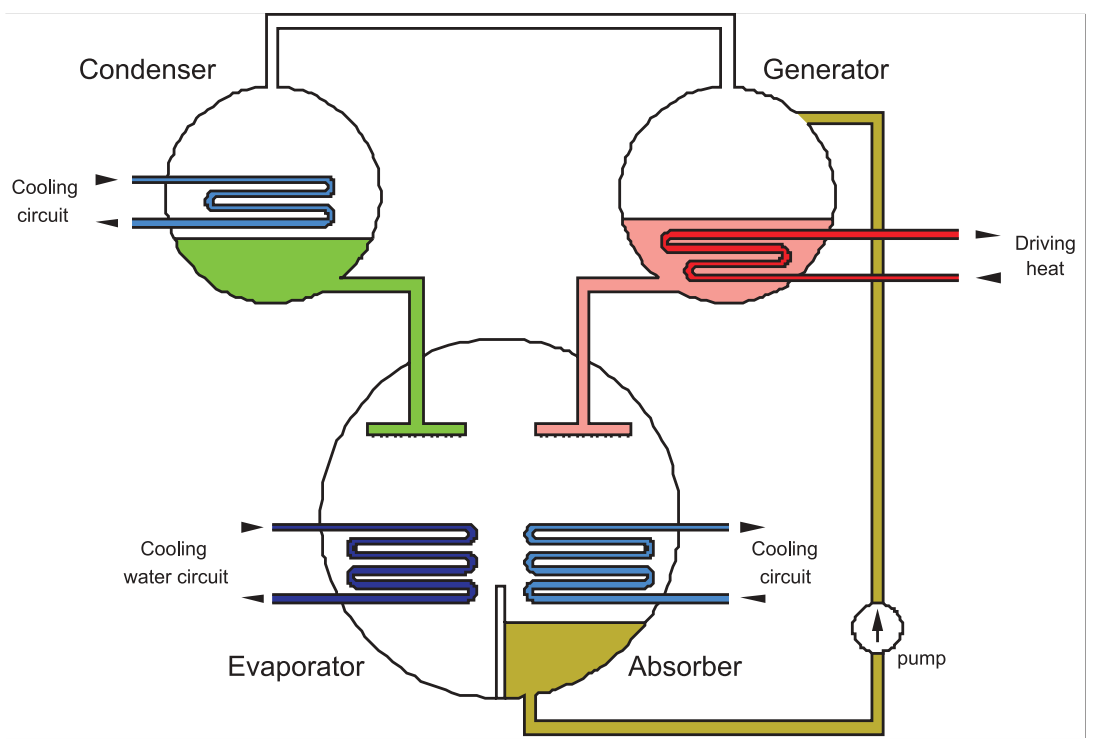

Figure 5. Absorption refrigeration device. 


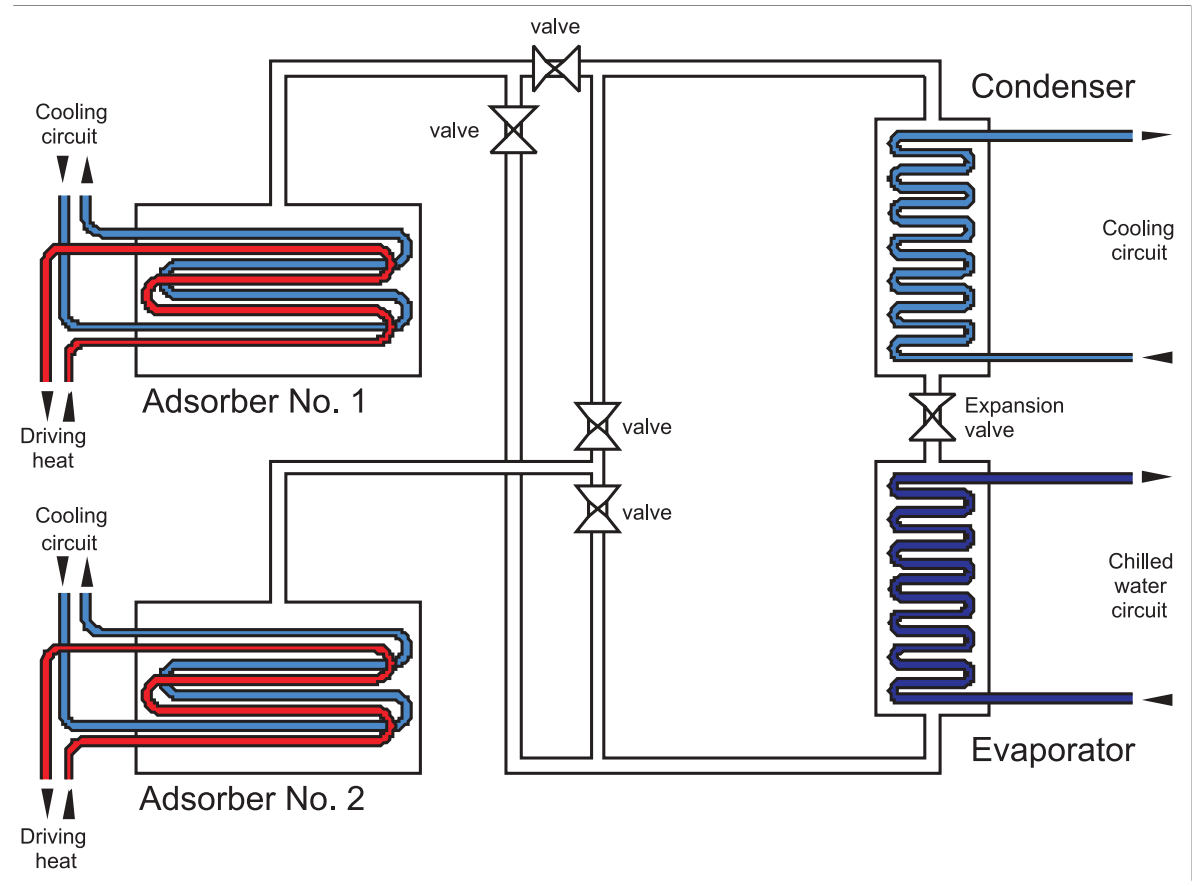

Figure 6. Adsorption refrigeration device.

In the adsorption systems the working pairs spectrum is much higher, both on the refrigerant side and on the adsorbents side. As refrigerants the most common used are: methanol, ethanol, water, ammonia and as the adsorptive bad activated carbon, silica gels and zeolites are used $[1,11]$. Construction of adsorption device with two adsorbers is shown in Fig. 6 [5].

The main advantage of adsorption device, compared to the absorption equipment is that it can operate at considerably lower driving temperatures [13]. However, a major disadvantage is that the process takes place periodically. This is due to the fact that in the adsorption bed sorption substance is in the form of a solid. This causes that firstly heat must be supplied to one of the adsorber and then to the other. The result is that the cooling capacity varies with time because of the variable refrigerant stream [13].

The variation of the cooling capacity for absorption and adsorption system is shown in Fig. 7. This disadvantage of adsorption systems is eliminated by increasing the amount of adsorbers, or by using a tank to accumulate cold. 


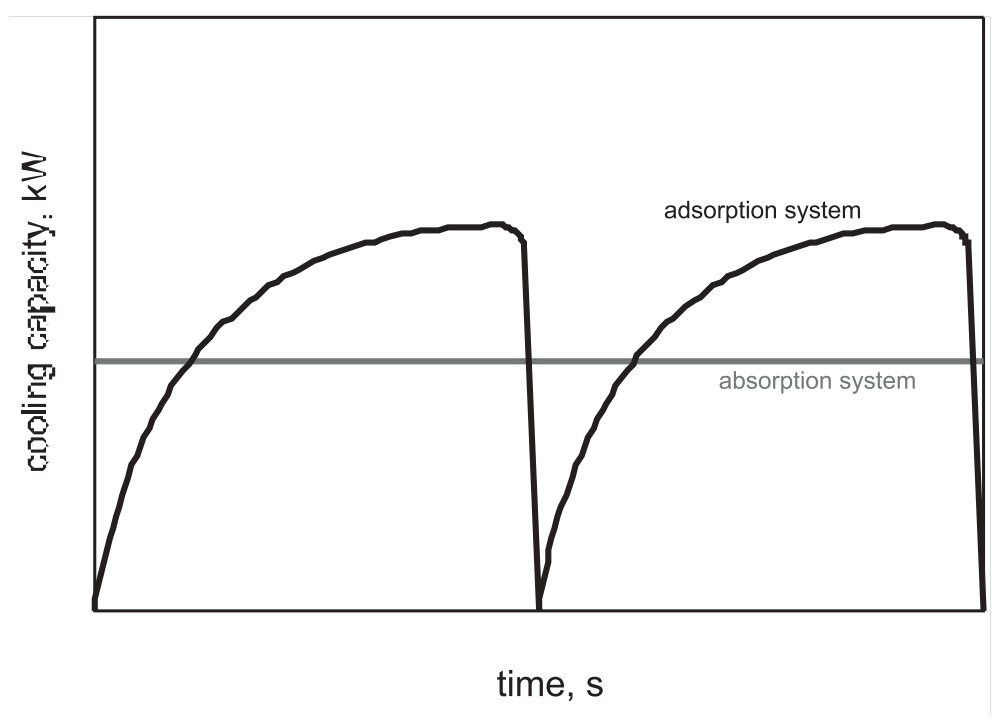

Figure 7. Cooling capacity as a function of the time.

Rest of this article will consider only adsorption systems because they can be used in all three types of trigeneration configurations.

\section{Efficiency of the adsorption process for genera- tion of cold}

Thermodynamic processes which occurs in the adsorbers are shown in Fig. 8. According to the theory described by Gacciola and Restuccia [3], during the heating process (line A-B-C), in the adsorber we deal with isosteric and isobaric processes. Throughout this process, it is necessary to supply heat to the system. Then the adsorber undergoes a change isosteric and isobaric during which heat is the sink (line C-D-A) [3]. In systems with two adsorbers while first adsorber passes successively united A-B-C, second adsorber passes C-D-A states.

Due to the fact that the process is periodical, all notations in the model are in the form of heat rather than heat fluxes.

Coefficient of performance $(C O P)$ is determined from the equation [5]

$$
C O P=\frac{Q_{e}}{Q_{d}}
$$




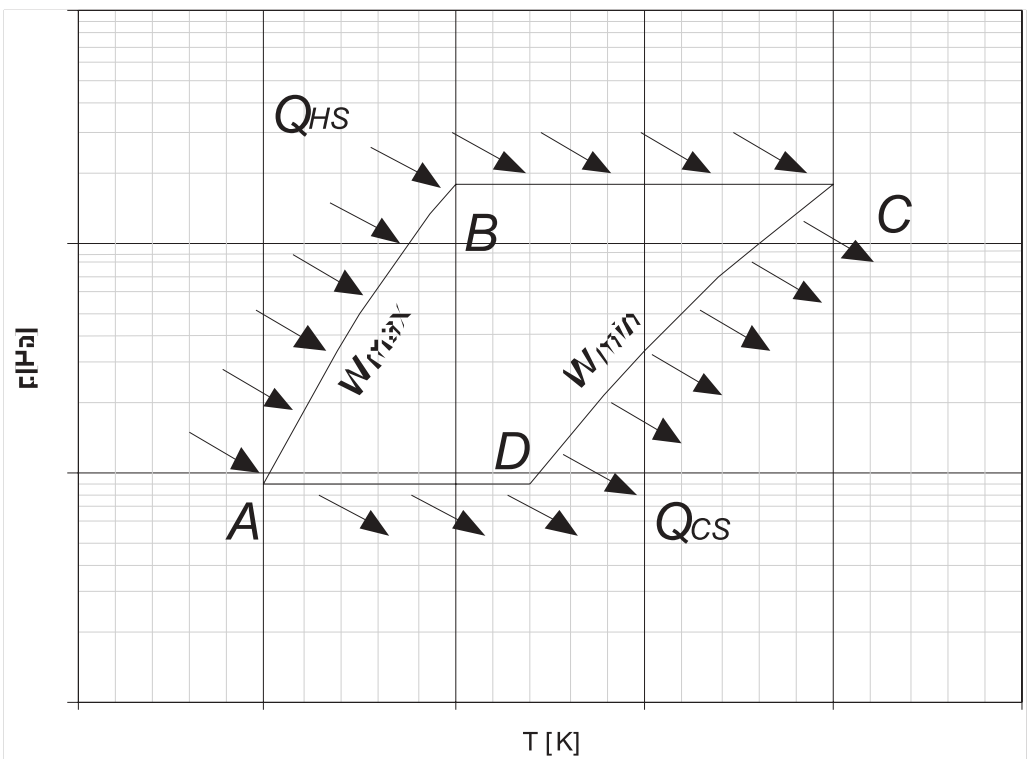

Figure 8. Adsorbers thermodynamic states.

where $Q_{e}$ is the amount of heat received by the evaporator in the entire half cycle, $Q_{d}$ is the amount of heat supplied to the adsorber in the half-period. The amount of heat received in the evaporator can be calculated from the equation [5]

$$
Q_{e}=m_{a d}\left(w_{\max }-w_{\min }\right) \Delta h_{e} .
$$

Line A-B-C in Fig. 8 shows changes of adsorber state during the desorption process. Thermal energy during this process is divided into a few parts:

$$
Q_{d}=Q_{i s}+Q_{d e s}+Q_{a}+Q_{a d} .
$$

First of them is isosteric part, represented by line A-B. In this part just adsorber content change temperature from $T_{A}$ to $T_{B}$

$$
Q_{i z}=m_{a d} \int_{T_{A}}^{T_{B}}\left[c_{a}(T)+c_{a f}(T) w_{\max }\right] d T .
$$

Second part is exact desorption process, represented by line B-C. During 
this part refrigerant uptake in adsorber decreases from $w_{\max }$ to $w_{\min }$

$$
Q_{d e s}=m_{a d} \int_{w_{\max }}^{w_{\min }} \Delta H(w) d w .
$$

Third one describes temperature change of adsorbent from $T_{B}$ to $T_{C}$, and is also represented by a line B-C in Fig. 8,

$$
Q_{a}=m_{a d} \int_{T_{B}}^{T_{C}} c_{a}(T) d T .
$$

The last one describes temperature change of adsorbate from $T_{B}$ to $T_{C}$. The difference between Eqs. (7) and (6) is a reason for changing the adsorbate uptake in adsorbent during this process

$$
Q_{a d}=m_{a d} \int_{T_{B}}^{T_{C}}\left(c_{a f}(T) w(T)\right) d T .
$$

Dependence of the cooling efficiency as a function of temperature of the heat source can be determined on the basis of the mathematical model. Calculations were performed for two working pairs, namely zeolite $13 \mathrm{X}$ with water, and the zeolite $4 \mathrm{~A}$ also cooperating with water. Figure 9 shows a clear correlation between the temperature of the driving heat source and cooling efficiency. Furthermore, it can be observed that zeolite $4 \mathrm{~A}+$ water are better solution at lower temperature, and zeolite $13 \mathrm{X}+$ water is better at the higher temperature of the driving heat source.

\section{Improving the efficiency of adsoprption devices}

Figure 8 shows that at the same time when the heating of adsorber 1 occurs, the adsorber 2 is cooled. In addition, the cooling occurs at higher temperature than heating. This fact can be used to improve the efficiency of the device.

In the previous section there was presented the model of a system in which the entire bed was treated as a deposit of the same temperature. To meet this requirement the device is necessary to be designed in appropriate way. It is clear from research, that it is not a perfect solution. Beside, 


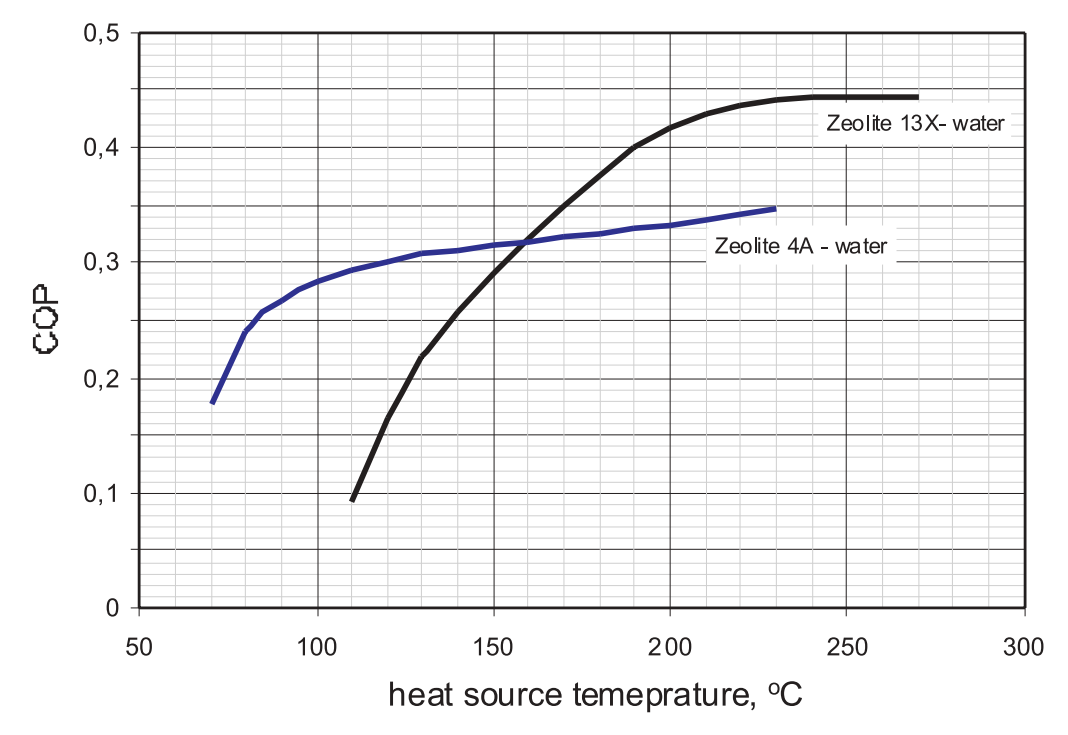

Figure 9. Coefficient of performance as function of driven heat source.

such construction makes the heat recovery difficult to be obtained at the beginning of the process. A much better solution is to use the devices called the thermal wave. Figure 10 presents adsorption system that allows heat recovery during the initial half-period. This recovery is based on the fact that the cold adsorber is heated by the working medium, which cools the second adsorber. Therefore, it is not done by an external heat flux. Energy profit that can be achieved is clearly presented in Fig. 11. Working fluid, after passing the adsorber 1 is already partially heated which means that the external heat flux may be a lower power, respectively. The same applies to the cooling capacity. Working fluid after passing the adsorber is cooled so that the required cooling capacity is lower. Thermal wave system allows heat recovery in the early stages of the half-cycle. The research shows that this solution can increase the $C O P$ by $25 \%$ [3,12]. The disadvantage of this solution compared to adsorption system described in Fig. 6 is that there should be added additional heat exchanger, between the heat source and the adsorber. Nevertheless, this situation often occurs also in systems presented in Fig. 6. 


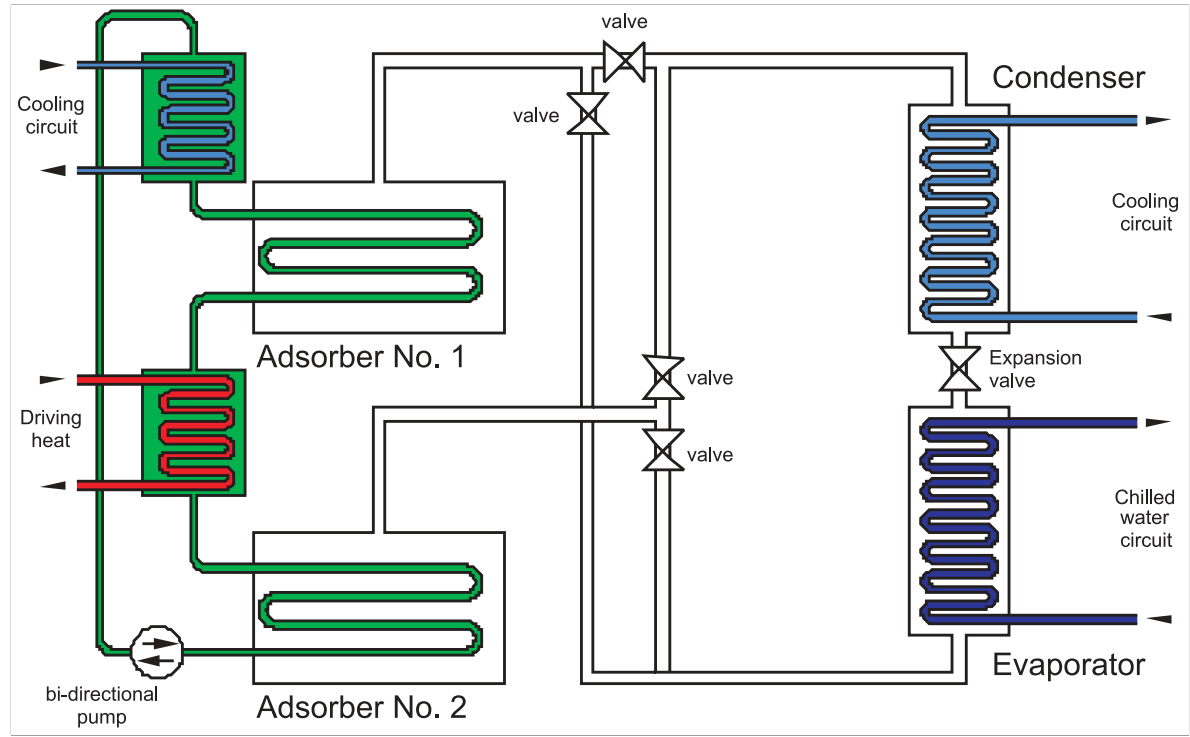

Figure 10. Thermal wave adsorption system.

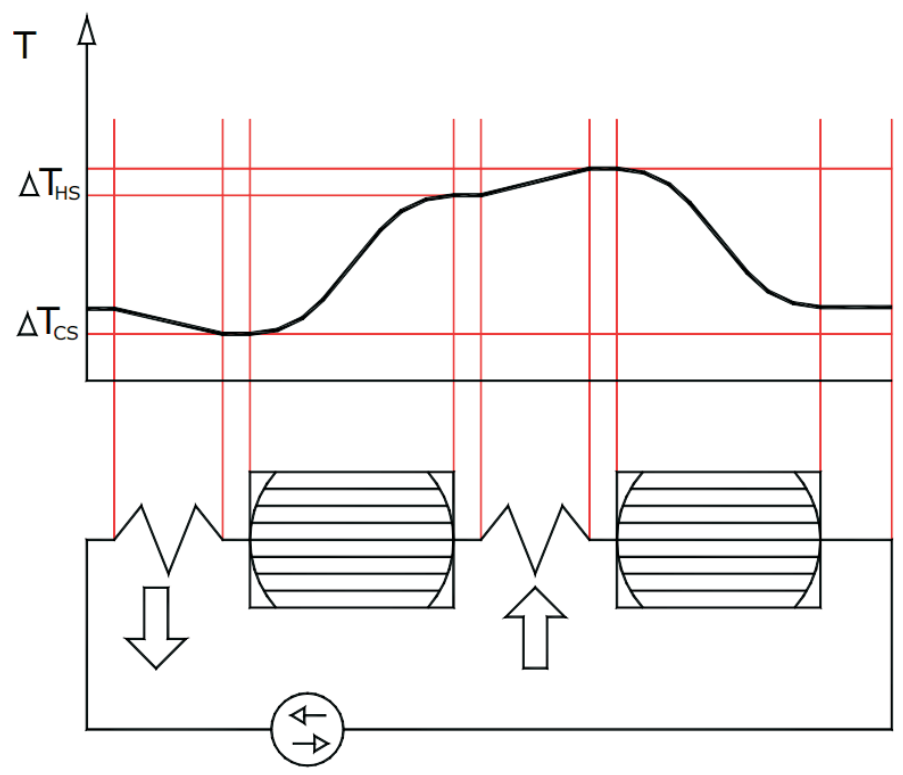

Figure 11. Working fluid temperature in thermal wave adsorption system. 


\section{$6 \quad$ Experimental studies}

In order to verify the effectiveness of the thermal wave adsorption device measurement station has been built according to Fig. 10. Methanol was tested as refrigerant, and the adsorption bed was made of activated carbon $[2,14]$. As the working fluid in the thermal wave circuit thermal oil was applied. In the cooling circuit there water was used. Electric heater was providing driving heat instead of the heat circuit.

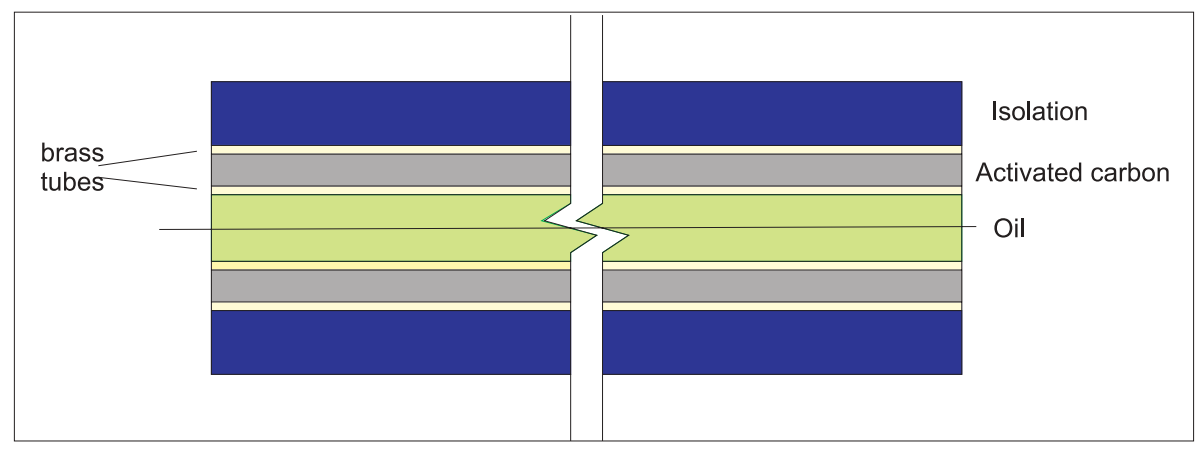

Figure 12. Adsorber cross-section.

Figure 12 presents the construction of the adsorbers, used in the test device oil flows in the inner tube. Hot oil from the electrical heater heated the adsorber bed, which causes desorption of methanol. Desorbed methanol flows to typical refrigeration system, that means the condenser, expansion valve and evaporator. The methanol then flows into the second adsorber where is sorbed, due to the fact that the oil from thermal wave circuit cools down the bed. Expansion valve has been used electrically operated. Plate heat exchangers were used as the evaporator, condenser and cooling circuit heat exchangers.

For determining the specific heat capacity of all heat exchangers temperature of working fluid before and after the heat exchangers was measured, as well as the fluid mass flow rate in a continuous manner. On the basis of these data basic parameters of the device were determined. Heat supplied during one half cycle was $Q_{d}=480 \mathrm{~kJ}$. The amount of heat received, at the same timeby the evaporator was $Q_{e}=134 \mathrm{~kJ}$ which gives the cooling efficiency $C O P=0.279$. The operating oil was heated up to a temperature of $95^{\circ} \mathrm{C}$. 


\section{Conclusions}

The paper presents some trigeneration ideas usable in urban systems. It is evident that the adsorption system can be used in three possible trigeneration systems. Absorption devices can not be used if the temperature falls below $90{ }^{\circ} \mathrm{C}$, and the manufacturers recommendations require that there should be a temperature above $110^{\circ} \mathrm{C}$. This fact eliminates them from use in centralized systems with decentralized cold generation. This is due to the fact that the greatest cooling demand is in the summer, when the temperature of the district heating water temperature is about $70^{\circ} \mathrm{C}$. In addition, the general trend in district heating systems in the world is to decrease the supply temperature even in winter, so here can be applied only adsorption units.

There was shown that the adsorption devices should be built in the form of the thermal wave, which allows its internal energy recovery and improves the efficiency of the entire system. It should also be remembered that the adsorbent bed slightly loses its character over time and after a number of cycles, the system performance will drop [6]. Another disadvantage of the adsorption devices is that they generate significantly more low-temperature waste heat than the compressor units. This is due to the low COP and also from the fact that heat is discharged not just from condenser, but also from adsorber during the sorption process.

Received 14 October 2013

\section{References}

[1] Askalany A.A., Salem M., Ismael I.M., Ali A.H.H., Morsy M.G., Saha B.B.: An overview on adsorption pairs for cooling. Renew. Sust. Energy Rev. 19(2013), 565-572.

[2] Buczek B., Klimowska E., Vogt E.: Preparation of active carbons for adsorption cooling system. Adsorption 11(2005), 769-773.

[3] Cacciola G., Restuccia G.: Reversible adsorption heat pump: A thermodynamic model. Int. J. Refrig. 18(1995), 2, 100-06.

[4] Grisel R.J.H., Smeding S.F., Boen R.: Waste heat driven silica gel/water adsorption cooling in trigeneration. Appl. Thermodyn. Eng. 30(2010), 1039-1046.

[5] Grzebielec A.: Experimental study on adsorption heat pump. Arch. Therm. 30(2009), 4, 189-200.

[6] Henninger S.K., Munz G., Ratzsch K.-F., Schossig P.: Cycle stability of sorption materials and composites for the use in heat pumps and cooling machines. Renew. Energy 36(2011), 3043-3049. 
[7] Hernandez-Santoyoa J., Sanchez-Cifuentes A.: Trigeneration: an alternative for energy savings. Appl. Energy 76(2003), 219-227.

[8] PolySMART: Poligeneration in Europe - A technical report. POLYgeneration with advanced Small and Medium scale thermally driven Air-conditioning and Refrigeration Technology, 2008-07-31.

[9] Rusowicz A., Ruciński A.: The mathematical modelling of the absorption machines used in energy systems. Environ. Eng. 1-3(2011), 802-806.

[10] Smyk A., Pietrzyk S.: Heat losses of the district heating network during different operational conditions. Rynek Energii 103(2012), 6, 46-51.

[11] Srivastava N.C., Eames I.W.: A review of adsorbents and adsorbates in solidvapour adsorption heat pump systems. Appl. Therm. Eng. 18(1998), 9-10, 707-714.

[12] Wang D.C., Li Y.H., Li D., Xia Y.Z., Zhang J.P.: A review on adsorption refrigeration technology and adsorption deterioration in physical adsorption systems. Renew. Sust. Energy Rev. 14(2010), 344-353.

[13] Wang L.W., BaO H.S., WAng R.Z.: A comparison of the performances of adsorption and resorption refrigeration systems powered by the low grade heat. Renew. Energy 34(2009), 2373-2379.

[14] Yeo T.H.C., Tan I.A.W., Abdullah M.O.: Development of adsorption airconditioning technology using modified activated carbon - A review. Renew. Sust. Energy Rev. 16(2012), 3355-3363. 